\title{
REMOVAL OF A BASIC DYE FROM AQUEOUS SOLUTION BY ADSORPTION USING RICE HULLS
}

\author{
A. EL-MAGHRABY \\ H.A. EL DEEB
}

\author{
Department of Fabrication Technology, \\ Institute of Advanced technology and New Materials, \\ Mubarak City for Scientific Research and Technology Applications, \\ Alexandria, Egypt
}

Received: $10 / 02 / 10$

Accepted: 30/06/10 *to whom all correspondence should be addressed: e-mail: maghrabyazza@yahoo.com

\begin{abstract}
The removal of dyes from colored effluents, particularly from textile industries, is one of the major environmental concerns these days. Current methods for removing dyes from wastewaters are costly and cannot effectively be used to treat wide range of such wastewaters. This work describes the use of grounded rice hull as adsorbent material. Aqueous solutions of various methylene blue dye concentrations (5-25 mg I$~^{-1}$ ) were shaken with certain amount of adsorbents to determine the adsorption capacity. Both treated and untreated rice hulls were used for methylene blue adsorption. The effects of adsorbents dose, initial $\mathrm{pH}$, initial dye concentration and contact time on dye removal have been studied. Maximum dye was sequestered from the solution within $60-90$ min after the beginning of every experiment. The adsorption capacity increased from 72 to $94 \%$ with increasing the $\mathrm{pH}$ from 3 to 10. Pretreatment of rice hulls with citric acid did not reveal any beneficial effect. Rice hulls were more effective compared to commercial used adsorbents used. The results showed that ground rice hulls can be considered as potential adsorbents for methylene blue removal from dilute aqueous solutions.
\end{abstract}

KEYWORDS: Bioadsorbent, Rice Hulls, Methylene blue, Agriculture waste.

\section{INTRODUCTION}

Dyes and pigments are one of the problematic groups of pollutants. They are discharged from various industries such as dyestuff manufacturing, dyeing, printing, and textile finishing. Most of the dyes are stable against photo degradation, bio-degradation, and oxidizing agents (Ramakrishna and Viraraghavan, 1997). Several methods have been used for the removal of dyes from the aquatic environment, including physical, chemical, and biological processes. Among these methods, adsorption is a widely used for dye removal from wastewaters (Bhattacharyya and Sharma, 2005). Lignocellulosic agricultural waste materials such as rice hulls, sugarcane bagasse, and wheat straw are now regarded as abundant, inexpensive, and readily available natural resources for chemical and paper industries (Theander and Aman, 1979; Gould, 1984.). Today's, the world's industry is utilizing less than $10 \%$ of biomass from plantations (Pauli and Gravitis, 1997). In Egypt, approximately 16 million tons of agricultural residues (AR) are currently disposed of every year the annual amount of rice hulls is about 3.6 million tones/year and many types of abundant AR especially from tropical plantations are waiting for effective utilization. AR are the most abundant renewable organic resource on the earth. AR have been utilized as renewable resources of energy and production of a diversity of chemicals, including ethanol (Ikeuchi et al., 1999), activated carbon (Namasivayan and Kadivelu, 1999), ion exchangers (Šimkovic and Laszlo, 1997). Many others application for AR are in the process of being developed. Annual world rice production is about 577 million metric tons (Kiran et al., 2000). The rice hulls which are discharged in large quantities at rice processing facilities or country elevators in rice cropping regions are utilized as farmyard compost, mulch and drainage materials, but the recycling rate of the rice hulls is about $10.0 \%$ (Woon et al., 2006). However, many countries have imposed new regulations to 
restrict field burning of rice hulls in response to restrictions on carbon emission due to global warning. This has helped simulate interest in the utilization of rice waste as a renewable natural resource. Various techniques have been employed for the removal of dyes from wastewaters (Choy et al., 1999; Gupta and Bhattacharya, 1985; Khattri and Singh, 2000; Kun-She et al., 2000; Liversidge et al., 1997; McKay et al., 1985; Mittal and Gupta, 1996; Perineau et al., 1982; Singh et al., 1984). Conventional physical and chemical methods are either costly, e.g. activated carbon, or produce concentrated sludge, e.g. Fenton's reagent, or may not be capable of treating large volumes of effluent without the risk of clogging, e.g. membrane filtration (Chuah et al., 2005). Natural materials that are available in large quantities, or certain waste product from industrial or agricultural processes, may have potential as inexpensive adsorbents. Rice hulls, an agricultural waste, have been reported as a good adsorbent of heavy metals. (Suemitsu et al., 1986; Marshall et al., 1993) The focus of the research is to evaluate the adsorption capacity of treated and untreated rice hulls for the adsorption of methylene blue dye from aqueous solutions. Methylene blue is the most commonly used material for dying cotton, wood and silk. Methylene blue was chosen because of its known strong adsorption onto solids and it serve as a model compound for removing organic contaminants and colored bodies.

\section{EXPERIMENTAL}

\subsection{Materials}

Rice hulls were used as precursor material of adsorbents. Rice hulls were obtained from local rice mills (Behra city-Egypt). The methylene blue dye (molecular formula: $\mathrm{C}_{16} \mathrm{H}_{18} \mathrm{~N}_{3} \mathrm{ClS}, \lambda_{\max }=655 \mathrm{~nm}$ ) used in this study was obtained from (Nice chemicals Pvt.Ltd).

Commercial adsorbents were also used for comparison (Table 1).

Table 1. Types of commercial adsorbents used

\begin{tabular}{|c|c|c|c|c|c|}
\hline $\begin{array}{l}\text { Adsorbent } \\
\text { type }\end{array}$ & Source & Composition & Appearance & Color & Specifications \\
\hline $\begin{array}{l}\text { 1-Adsorb-it } \\
\text { Filtration } \\
\text { Fabric }\end{array}$ & $\begin{array}{l}\text { Eco-Tec, Inc, } \\
\text { U.S.A. }\end{array}$ & $\begin{array}{l}\text { A geo- textile } \\
\text { quality non-woven } \\
\text { filtration fabric } \\
\text { manufactured from } \\
100 \% \text { recycled } \\
\text { select fibers from } \\
\text { the textile industry }\end{array}$ & $\begin{array}{l}\text { Thin sheet, no } \\
\text { odor }\end{array}$ & White gray & thickness $3.73 \mathrm{~mm}$ \\
\hline $\begin{array}{l}\text { 2-Adsorb- } \\
\text { it/AM } \\
\text { Antimicrobi } \\
\text { al Filtration } \\
\text { Fabric }\end{array}$ & $\begin{array}{l}\text { Eco-Tec, Inc, } \\
\text { U.S.A. }\end{array}$ & $\begin{array}{l}\text { Fabric of Adsorb-it } \\
\text { treated with a } \\
\text { surface bonded } \\
\text { non-leaching } \\
\text { antimicrobial }\end{array}$ & $\begin{array}{l}\text { Have two } \\
\text { surfaces one is } \\
\text { more rough } \\
\text { than the other } \\
\text { one, no odor, } \\
\text { thin sheet }\end{array}$ & Dark gray & thickness $3.8 \mathrm{~mm}$ \\
\hline $\begin{array}{l}\text { 3-Oil-Only } \\
\text { sorbent }\end{array}$ & $\begin{array}{l}\text { ARCUS } \\
\text { Absorbents } \\
\text { Inc, Toronto, } \\
\text { Ontario } \\
\text { Canada }\end{array}$ & $\begin{array}{l}\text { It consists of a } \\
\text { hydrophobic } \\
\text { polypropylene } \\
\text { product }\end{array}$ & $\begin{array}{l}\text { light weight, } \\
\text { flame resistant, } \\
\text { non-toxic }\end{array}$ & White color & $\begin{array}{l}\text { Available pad form } \\
\text { with size } \\
17^{\prime \prime} \times 19^{\prime \prime} \times 0.69 " \text {. }\end{array}$ \\
\hline
\end{tabular}

\subsection{Preparation of adsorbent}

Rice hulls were received grounded from local rice mills and then start to prepare samples.

\section{Untreated rice hulls:}

Rice hulls were washed four times with tap water, and then dried at $105^{\circ} \mathrm{C}$ for $2 \mathrm{~h}$. The rice hulls were sieved to $250-500 \mu \mathrm{m}$, and used for the study.

Treated rice hulls:

Rice hulls were washed four times with tap water, and then dried at $105^{\circ} \mathrm{C}$ for $2 \mathrm{~h}$. Soaking it for $2 \mathrm{~h}$ in citric acid $0.6 \mathrm{M}$ at room temperature was applied to activate the rice hulls which were then 
sieved to $250-500 \mu \mathrm{m}$. The acid- hulls slurry was dried over night at $50^{\circ} \mathrm{C}$ then the hulls were boiled at $100{ }^{\circ} \mathrm{C}$ for one hour and then washed with distilled water $\left(200 \mathrm{ml} \mathrm{g}^{-1}\right.$ of hulls) to remove any excess of citric acid followed by overnight drying at $105^{\circ} \mathrm{C}$.

\subsection{Preparation of dye solution}

A stock solution of the dye was prepared by dissolving $1.0 \mathrm{~g}$ of dye in $1000 \mathrm{ml}$ distilled water to make a stock solution of $1000 \mathrm{mg} \mathrm{I}^{-1}$. The experimental solution was prepared by diluting definite volume of the stock solution to get the desired concentration. For absorbance measurements a spectrometer UV-VIS double beam PC scanning (Lambomed. INC) was employed, the rice hulls was gravity separation before sampling .The maximum wavelength $\lambda_{\max }$ for the methylene blue was measured at $655 \mathrm{~nm}$. Concentrations during experimental work were determined from a standard calibration curve.

\subsection{Adsorption Studies}

Equilibrium adsorption isotherms using raw and treated rice hulls with different amount $\left(5,10,15 \mathrm{~g} \mathrm{l}^{-1}\right)$ were determined at agitation rate of $150 \mathrm{rpm}$, room temperature $\left(26+1{ }^{\circ} \mathrm{C}\right)$ and with different concentrations of dye $\left(5-25 \mathrm{mg} \mathrm{l}^{-1}\right)$. Adsorbent dosage (based on dry weight of rice hulls) was placed in a set of $100 \mathrm{ml}$ beaker and different initial dye concentrations were added to each beaker. The contents were shaken for 2 hours the solution was analyzed for dye contents. The adsorption behaviors of the samples were studied by evaluating the percentage removal efficiency of methylene blue, calculated as

Removal efficiency $=\left[\left(\mathrm{C}_{0}-\mathrm{C}\right) / \mathrm{C}_{0}\right] \times 100$

Where $\mathrm{C}_{0}$ is the initial concentration of methylene blue, $\mathrm{C}$ is the solution concentration after adsorption at any time. The effect of adsorption time on the dye removal at various predetermined intervals from (10-120 min) using spectrometer UV-VIS double beam PC scanning for measurement of concentration at $\lambda_{\max }=655 \mathrm{~nm}$ was monitored by shaking the reaction mixture and analyzed for the dye content at the end of each contact time.

\subsection{Equilibrium studies}

The amount of adsorption for untreated and treated rice hulls, $\mathrm{q}_{\mathrm{e}}\left(\mathrm{mg} \mathrm{g}^{-1}\right)$, was calculated by $q_{e}=\left(\mathrm{C}_{0}-\mathrm{C}_{\mathrm{e}}\right) \mathrm{V} / \mathrm{W}$

where $C_{0}$ and $C_{\mathrm{e}}\left(\mathrm{mg} \mathrm{l}^{-1}\right)$ are the liquid-phase concentrations of dye at initial and equilibrium, respectively. $V$ is the volume of the solution (I) and $W$ is the mass of dry sorbent used (g).

\section{RESULT AND DISCUSSION}

Dyes are widely used in industries such as textiles, rubber, paper, plastic, cosmetics, etc. to color these products and the dyes invariably remain important source of pollution. Many of the organic dyes are hazardous and may affect aquatic life. The removal of dyes from wastewater is an essential task for environmental protection so various techniques have been employed for removal of dyes from wastewater. Natural materials or certain waste product from agricultural operations may have potential as inexpensive adsorbents, due to their low cost, while they can be disposed of without expensive regeneration.

\subsection{Effect of adsorbent mass}

The effect of adsorbent amount on the uptake of the dye was measured for dye concentration 10 $\mathrm{mg} \mathrm{I}^{-1}$, different shaking time (10-240 min) and different quantity of rice hulls $(5,10$, and $15 \mathrm{~g})$ at $\mathrm{pH}$ 7 and room temperature $\left(26 \pm 1^{\circ} \mathrm{C}\right)$.(Figure 1a, b). In general, it was found that by increasing the amount of the adsorbent the adsorption rate increased. This increase was most significant when the amount of adsorbent increased from (5-15 $\left.\mathrm{g} \mathrm{I}^{-1}\right)$. Maximum dye removal was achieved within 60-90 minutes after which a decrease in methylene blue concentration was negligible. Increase in dye removal percentage with adsorbent dose can be attributed to increased adsorbent surface area and availability of more adsorption sites. At the beginning of the process the rate of dye removal by the rice hulls was fast during the first $30 \mathrm{~min}$ and then decreased gradually. 


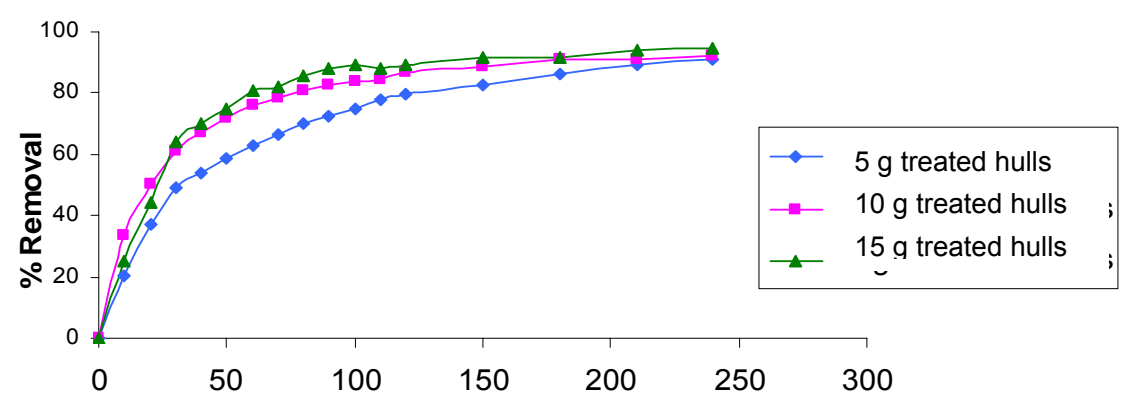

Figure 1a. Effect of amount of untreated rice hulls on the removal of dye

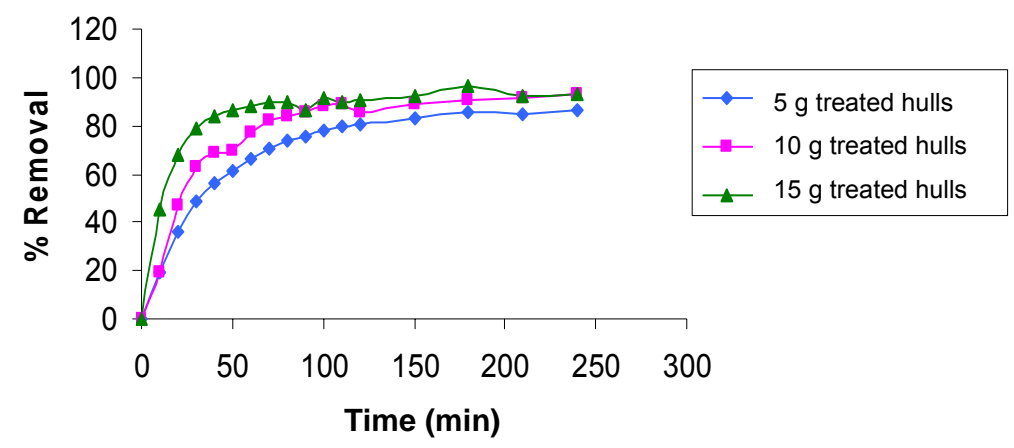

Figure 1b. Effect of amount of treated rice hulls on dye removal

\subsection{Comparison of treated and untreated rice hulls}

The effect of treating the rice hulls was studied at fixed adsorbent dose $10 \mathrm{~g}$ hulls, temperature (26 $\pm 1{ }^{\circ} \mathrm{C}$ ), with initial concentration of methylene blue $10 \mathrm{mg} \mathrm{I}^{-1}$ and $\mathrm{pH}$ neutral for different time intervals. It is evident from Figure 2 that the adsorption of the dye with treated hulls was higher than the untreated and equilibrium was established in about $90 \mathrm{~min}$.

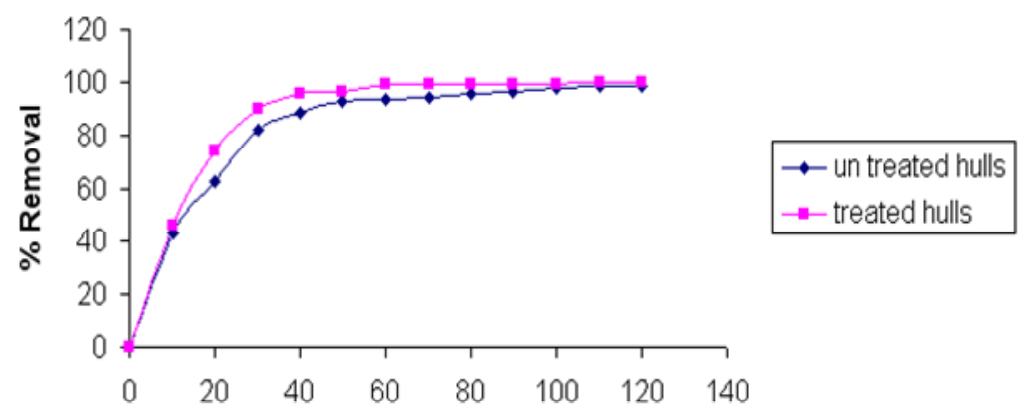

Figure 2. Effect of chemical treatment of rice hulls on methylene blue adsorption

\subsection{Effect of initial dye concentration}

The influence of the initial concentration of methylene blue $\left(5-25 \mathrm{mg} \mathrm{l}^{-1}\right)$ on the adsorption rate using untreated and treated rice hulls was studied. The experiments were carried out at fixed adsorbent dose $(10 \mathrm{~g})$, at room temperature $\left(26 \pm 1^{\circ} \mathrm{C}\right)$, neutral $\mathrm{pH}(7.0)$ for $30 \mathrm{~min}$.

Dye removed by treated and untreated rice hulls were about $90 \%$ after $30 \mathrm{~min}$. The removal efficiency of the two adsorbents decreased with increasing initial dye concentration. Table 2 shows that the percent adsorption decreased with increase in initial dye concentration, but the actual amount of dye adsorbed per unit mass of adsorbent increased with increase in dye concentration in the test solution for different concentrations $\left(5-25 \mathrm{mg} \mathrm{l}^{-1}\right)$ at the same time (min). 
Table 2. Effect of methylene blue concentration on dye adsorption

\begin{tabular}{|c|c|c|c|c|c|c|}
\hline \multirow{2}{*}{$\begin{array}{l}\text { Initial dye } \\
\text { concentration } \\
\left(\mathrm{mg} \mathrm{l}^{-1}\right)\end{array}$} & \multicolumn{6}{|c|}{ Percent dye removal with time(min) } \\
\hline & 10 & 20 & 30 & 40 & 50 & 60 \\
\hline \multicolumn{7}{|c|}{ Untreated rice straw } \\
\hline 5 & 65.46 & 80.22 & 82.86 & 98.23 & 90.2 & 98.84 \\
\hline 10 & 42.9 & 62.18 & 82.1 & 88.23 & 92.9 & 98.59 \\
\hline 15 & 41.97 & 53.57 & 67.63 & 74.84 & 80.19 & 86.38 \\
\hline 20 & 41.16 & 58.82 & 70.185 & 75.23 & 79.69 & 85.37 \\
\hline 25 & 38.67 & 56.96 & 62.98 & 66.23 & 66.99 & 72 \\
\hline \multicolumn{7}{|c|}{ Treated rice straw } \\
\hline 5 & 81.1 & 85.2 & 89.98 & 96.35 & 98.8 & 98.97 \\
\hline 10 & 46.2 & 73.9 & 89.85 & 95.7 & 96.25 & 97.8 \\
\hline 15 & 36.63 & 65.89 & 78.57 & 80.01 & 86.32 & 90.65 \\
\hline 20 & 29.04 & 48.46 & 68.92 & 73.43 & 78.25 & 80.22 \\
\hline 25 & 32.01 & 54.51 & 71.28 & 75.60 & 78.06 & 79.34 \\
\hline
\end{tabular}

The unit adsorption for untreated rice hulls increased from $0.41 \mathrm{mg} \mathrm{g}^{-1}$ to $1.57 \mathrm{mg} \mathrm{g}^{-1}$ as the methylene blue concentration in the test solution was increased from 5 to $25 \mathrm{mg} \mathrm{l}^{-1}$. Similarly, unit adsorption for treated rice hulls increased from $0.45 \mathrm{mg} \mathrm{g}^{-1}$ to $1.78 \mathrm{mg} \mathrm{g}^{-1}$ as the methylene blue concentration in the test solution increased from 5 to $25 \mathrm{mg} \mathrm{l}^{-1}$. Maximum dye was sequestered from the solution within 15 min (30 or 90 as previously) after the beginning for every experiment. Thereafter, the decrease of methylene blue concentration was negligible.

\subsection{Effect of $\mathrm{pH}$}

The $\mathrm{pH}$ value of the solution is an important parameter for the adsorption processes, and the initial $\mathrm{pH}$ value of the solution has significant influence compared to than the final $\mathrm{pH}$ (Hem et al., 2007). To study the effect of $\mathrm{pH}$ on methylene blue adsorption, the experiments were carried out at $10 \mathrm{mg} \mathrm{I}^{-1}$ initial dye concentration with $10 \mathrm{~g} \mathrm{I}^{-1}$ adsorbent dosage at $\left(26 \pm 1^{\circ} \mathrm{C}\right)$. In general, initial $\mathrm{pH}$ value may enhance or depress the uptake. This is attributed to the charge of the adsorbent surface with the change in $\mathrm{pH}$ value. Figure 3 shows the relationship between the $\mathrm{pH}$ value and the removal of methylene blue. It can seen from the figure that as the solution $\mathrm{pH}$ increases, the adsorption capacity increases. Increasing solution $\mathrm{pH}$ increases the number of hydroxyl groups thus, increases the number of negatively charge sites and enlarges the attraction between dye and adsorbent surface' (Lai and Chen, 2001). Generally, the net positive charge decreases with increasing $\mathrm{pH}$ value lead in the decrease in the repulsion between the adsorbent surface and the dye thus, improving the adsorption capacity.

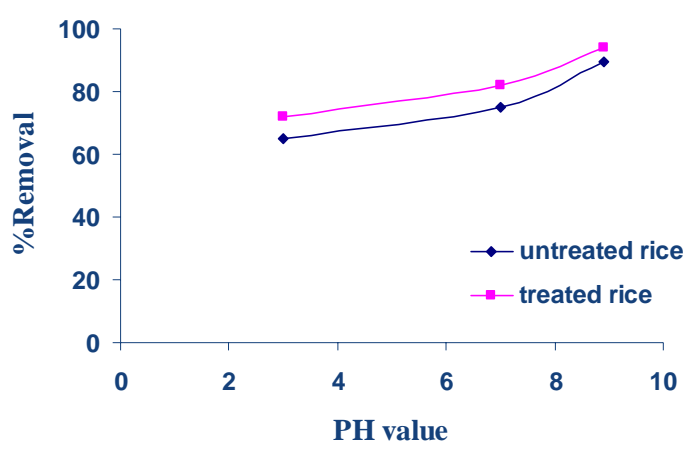

Figure 3. Effect of $\mathrm{pH}$ on methylene blue adsorption

\subsection{Isotherm analysis}

The purpose of the adsorption isotherms is to relate the adsorbent concentration in the bulk solution and the adsorbed amount at the interface (Eastoe and Dalton, 2000). The equilibrium isotherms in this study have been described in terms of Freundlich isotherms.

The Freundlich isotherm (Freundlich, 1906) is an empirical equation assuming that the adsorption process takes place on heterogeneous surfaces and adsorption capacity is related to the 
concentration of methylene blue dye at equilibrium. A linear form of the Freundlich equation is generally expressed as follows:

$$
\ln q_{e}=\ln \mathrm{K}_{\mathrm{F}}+(1 / \mathrm{n}) \ln \mathrm{C}_{\mathrm{e}}
$$

where $K_{F}\left(\mathrm{mg} \mathrm{g}^{-1}(\mathrm{l} \mathrm{mg})^{-1 / n}\right)$ is roughly an indicator of the adsorption capacity and $1 / n$ is the adsorption intensity. The magnitude of the exponent, $1 / n$, gives an indication of the favorability of adsorption. Values of $n>1$ represent favorable adsorption condition (Treybal, 1968). The plot of In $q_{\mathrm{e}}$ versus $\ln C_{\mathrm{e}}$ (Fig. 4-5) is employed to evaluate the intercept $K_{\mathrm{F}}$ and the slope $1 / n$. The values of $K_{\mathrm{F}}, n$ and the linear regression correlation $\left(R^{2}\right)$ for Freundlich are given in Table 3.
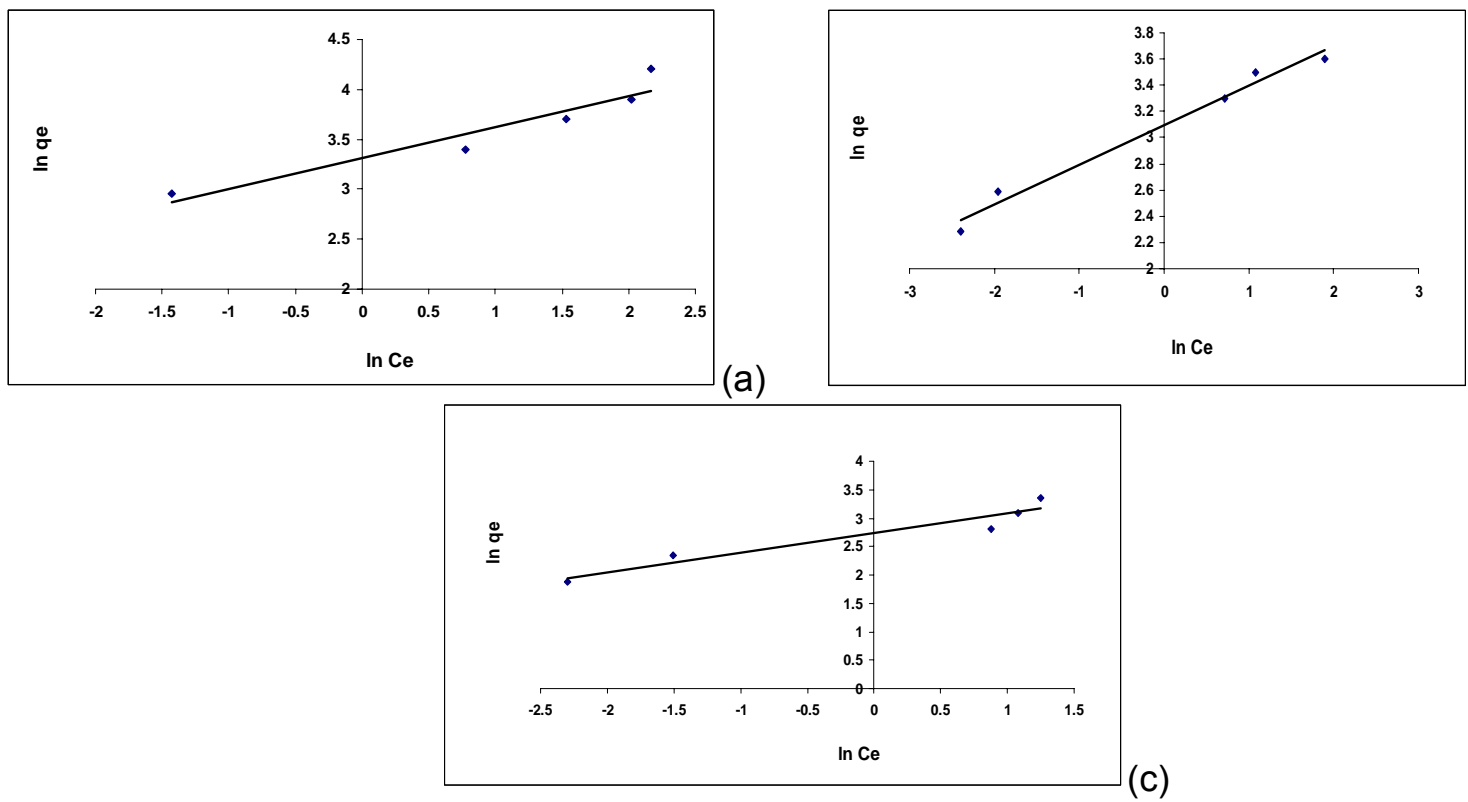

Figure 4. Freundlich isotherm of methylene blue adsorption onto untreated rice hulls (a) $5 \mathrm{~g}$, (b) $10 \mathrm{~g}$, (c) $15 \mathrm{~g}$

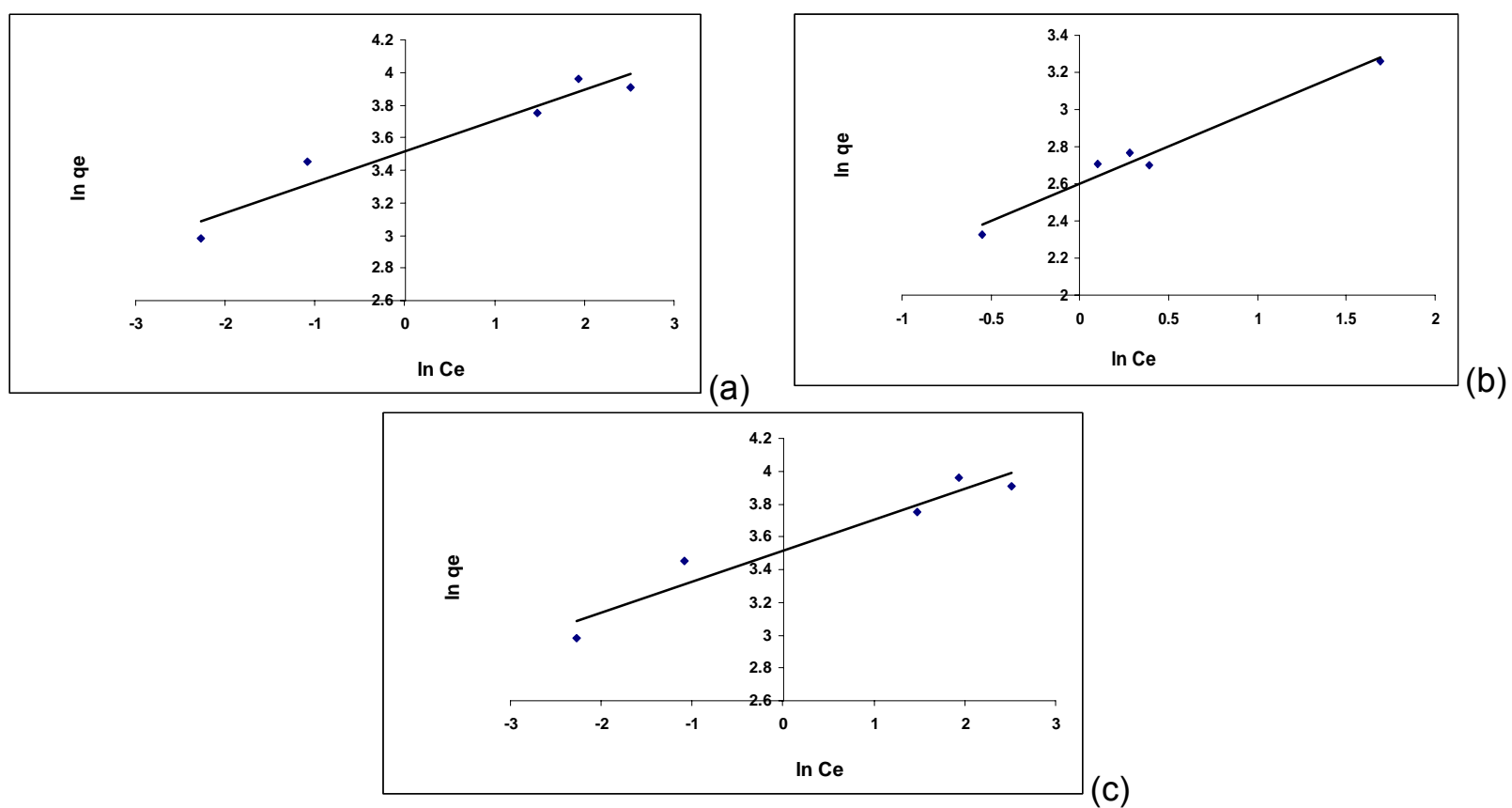

Figure 5. Freundlich isotherm of methylene blue adsorption onto treated rice hulls (a) $5 \mathrm{~g}$, (b) $10 \mathrm{~g}$, (c) $15 \mathrm{~g}$ 
Table 3. Isotherm parameters for removal of methylene blue by untreated and treated rice hulls

\begin{tabular}{|c|c|c|}
\hline \multirow{2}{*}{ Isotherm } & \multicolumn{2}{|c|}{ Parameters } \\
\hline & Untreated rice hulls & Treated rice hulls \\
\hline \multicolumn{3}{|c|}{ 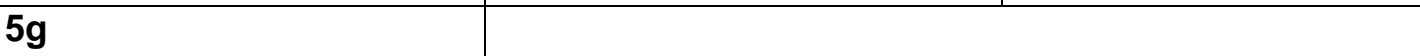 } \\
\hline $\mathrm{n}$ & 3.2 & 5.32 \\
\hline $\mathrm{K}_{\mathrm{F}}$ & 27.54 & 33.56 \\
\hline $\mathrm{R}^{2}$ & 0.9075 & 0.9306 \\
\hline \multicolumn{3}{|l|}{$10 \mathrm{~g}$} \\
\hline$n$ & 3.32 & 4.67 \\
\hline $\mathrm{K}_{\mathrm{F}}$ & 22.1 & 15.5 \\
\hline $\mathrm{R}^{2}$ & 0.9803 & 0.979 \\
\hline \multicolumn{3}{|l|}{$15 \mathrm{~g}$} \\
\hline $\mathrm{n}$ & 2.9 & 2.49 \\
\hline $\mathrm{K}_{\mathrm{F}}$ & 15.44 & 13.5 \\
\hline $\mathrm{R}^{2}$ & 0.9167 & 0.9677 \\
\hline
\end{tabular}

3.6. Comparison between the raw, treated rice hulls and commercial adsorbents

The adsorption of methylene blue onto three different commercial adsorbents (as these adsorbents are used in the market for other sorption processes as oil sorption, so we choose this commercial adsorbent to evident the availability of using these in dye removal and comparing with the rice hulls and it used in pad form contain granules of the adsorbent, using this types instead of using activated carbon because many researches interested in this type of adsorbent), treated and untreated rice hulls was studied at fixed adsorbent quantity $(10 \mathrm{~g})$, temperature $\left(26 \pm 1{ }^{\circ} \mathrm{C}\right)$ and neutral $\mathrm{pH}$ for a 120 min period. It is evident from Figure (6) that the adsorption capacity of the treated and untreated rice hulls is higher compared to commercial adsorbents except for oil adsorbent which revealed higher percentage removal during the first 60 minutes and following this, the adsorption of rice hulls were almost equal, which confirm that this waste can be used as an adsorbent.

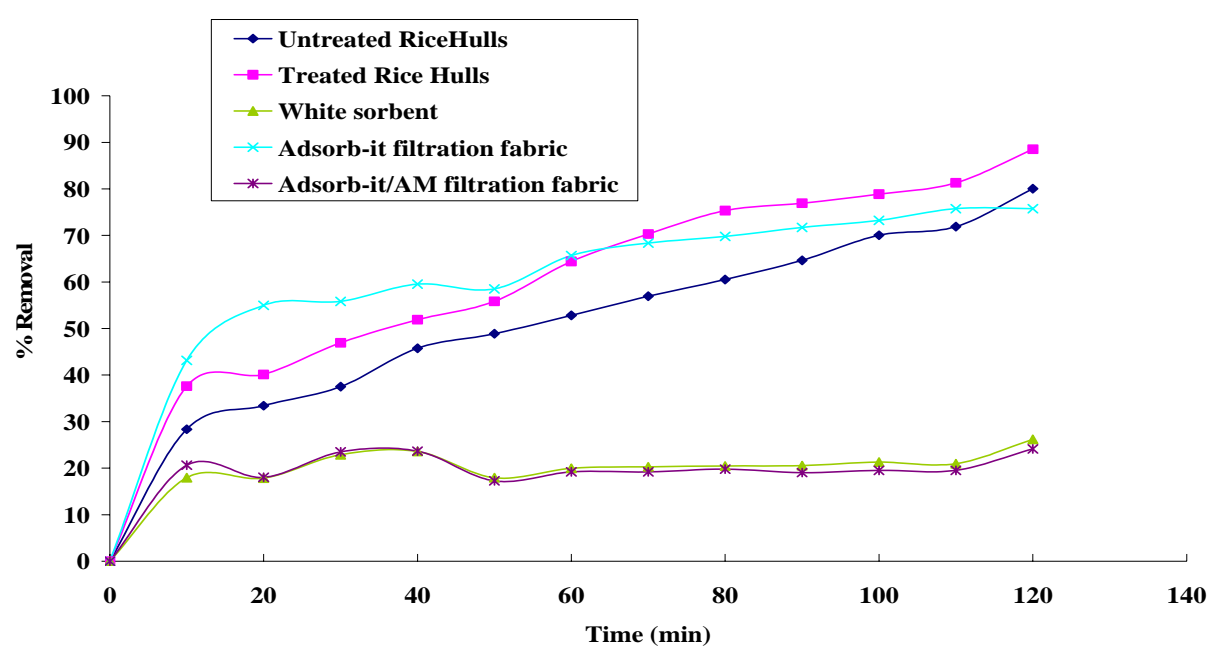

Figure 6. Comparison between commercial sorbents and rice hulls residue treated and untreated

\subsection{Technology importance, separation technique and disposal}

Natural fibers have little resistance towards environmental influences and show an intrinsic variability of their properties (Joseph et al., 2002). Rice hulls were chosen to be applied as adsorbent material due to its fibrous structure, insolubility in water, chemical stability, high mechanical strength and its local availability at almost no cost. The advantage in the application of this waste is that there is no need to regenerate them because of their low production costs 
(Daifullah et al., 2003). Furthermore, separation of the rice hulls from the treated water is possible by a simple settling process. The rice husks which are discharged after dye removal can be used as insulating material (walls, floors or roofs) and for manufacture of particle boards.

\section{CONCLUSIONS}

Biosolid is a promising adsorbent for removal of the cationic dyes. The removal of methylene blue from wastewater using grounded rice hulls has been investigated under different experimental conditions in batch mode. The adsorption of dye was dependent on adsorbent dose and methylene blue concentration in wastewater. Initial $\mathrm{pH}$ of solution affected the adsorption of this dye. The optimum $\mathrm{pH}$ for the removal of methylene blue from aqueous solution under the experimental conditions used in this work was 10. Maximum dye removal was observed within 30 min from the beginning of each experiment. No pretreatment is necessary as sufficient dye removal is achieved by the untreated material. The present investigation showed that rice hulls can be effectively used as adsorbent comparable with the three commercial adsorbents used. Rice hulls are economically cheap and so regeneration is not necessary. Rice hulls are unwanted waste agriculture, would be useful for the economic treatment of dyeing effluent.

\section{REFERENCES}

Bhattacharyya K.G. and Sharma A. (2005) Kinetics and mechanism of removal of methylene blue by adsorption on various carbons-a comparative study, Dyes and pigments, 51, 25-40.

Choy K.K.H., McKay G. and Porter J.F. (1999) sorption of acid dyes from effluent using activated carbon, Resour.Conserv. Recy, 27, 57-71.

Chuah T.G., Jumasiah A., Azni I., Katayon S. and Thomas Choong S.Y. (2005) Rice husk as a potentially low-cost biosorbent for heavy metal and dye removal: an overview, Desalination, 175(3), 305-316.

Daifullah A.A.M., Girgis B.S. and Gad H.M.H. (2003) Utilization of agro-residues(rice husk) in small waste water treatment plans, Materials Letters, 75, 1723-1731.

Eastoe J. and Dalton J.S. (2000) Dynamic surface tension and adsorption mechanisms of surfactants at the airwater interface, Adv. Colloid Interface Sci., $85,103-144$.

Freundlich H. (1906), Umber die adsorption in lösungen [Adsorption in solution] Z.Phys. Chem., 57, 384-470.

Gould J.M. (1984) Alkaline peroxide delignification of agricultural residues to enhance, Biotechnology and Bioengineering, 26, 46-52.

Gupta M.P. and Bhattacharya P.K. (1985), Studies on color removal from bleach plant effluent of a craft pulp, Chem. Technol Biotechnol, 35B, 23-28.

Gupta S., Pal A., Ghosh P.K. and Bandyopadhyay M. (2003) Performance of waste activated carbon as a low-cost adsorbent for the removal of anionic surfactant from aquatic environment, J. Environ. Sci. Health, A38, 381-397.

Hem L., Garg V.K. and Gupta R.K. (2007) Removal of a basic dye from aqueous solution by adsorption using parthenium hysterophorus: An agricultural waste, Dyes and Pigment, 74, 653-658.

Ho Y.S. and McKay G. (1978) Sorption of dye from aqueous solution by peat, Chem. Eng. J., 70, 115124.

Ikeuchi T., Azumaa M., Katoa J. and Ooshima H. (1999) Screening of microorganisms for Xylitol production and ferementation behavior in high concentrations of xylose, Biomass \& Bioenergy, 16(5),333-339.

Joseph P.V., Rabello M.S., Mattoso L.H.C., Josef K. and Thomas S. (2002), Environmental effects on the degradation behaviour of sisal fiber reinforced polypropylene composites, Compos. Sci. Technol., 62(10/11), 1357-1372.

Kiran L., Kadam H., Loyd F., Jacobson A.W., (2000), Rice straw as a lignocellulosic resource:collection,processing,transportation, and environmental aspects, Biomass \& Bioenergy, 18, 369-389.

Khattri S.D. and Singh M.K. (2000), Color removal from synthetic dye wastewater using a bioadsorbent, Water Air Soil Poll., 120 ,283-294.

Kun-She L., Chnoong-Kheng L. and Bee-Foong T. (2000), Quaternised wood as sorbent for reactive dyes, App. Biochem. Biotectnol., 87, 233-245.

Lai C.H. and Chen C.Y. (2001), Removal of metal ions and humic acid from water by iron- coated filter media, Chemosphere, 44, 1177-1184. 
Liversidge R.M., Lloyd G.J., Wase D.A.J. and Forster C.F. (1997), Removal of Basic Blue 41 dye from aqueous solution by linseed cake, Process Biochemistry, 32, 473-477.

Marshall W.E., Champagne E.T. and Evans W.J. (1993), Use of rice milling by products (hulls and bran) to remove metal ions as aqueous solution, J. Environ. Sci. Health, A28, 1977-1992.

McKay G., Otterburn M.S. and Sweeney A.G. (1985), Fullers earth and fired clay as adsorbents for dye stuffs equilibrium and rate studies, Water Air Soil Poll., 24, 147-161.

Mittal A.K. and Gupta S.K. (1996), Biosorption of cationic dyes by dead macro fungus Fomitopsis carnea: batch studies, Water Sci. Technol., 34, 81-87.

Namasivayan C. and Kadivelu K. (1999), Up take of mercury (II) from waste water by activated carbon from an unwanted agricultural solid by- products: coir pith , Carbon, 37, 79- 84.

Pauli G. and Gravitis J. (1997), Environmental management of plantations: Through zero Emission Approach- plantation management for the $21^{\text {st }}$ century. Proceedings of the international planters conference on plantation management for the $21^{\text {st }}$ century, Kuala Lumpur, Malaysia., The incorporated society of planters, $1,193-207$.

Perineau F., Molinier J. and Gaset A.J. (1982), Adsorption of ionic dyes onto charred plant-material , J.Chert Technol. Biotechnol., $32,749-758$.

Ramakrishna K.R., and Viraraghavan T.V. (1997), Dye removal using low coast adsorbents, Water Science and Technology, 36, 189-196.

Šimkovic I. and Laszlo J.A. (1997), Preparation of ion exchangers from bagasse by cross linking with epichlorohydrin- $\mathrm{NH} 4 \mathrm{OH}$ or epichlorohydrin imidazole, J. Appl. Polym. Sci., 64,13, 2561- 2566.

Singh V.N., Mishra G. and Panday K.K. (1984) ,Removal of Congo red by wallastonite, Ind. J. Technol., $22,70-71$.

Suemitsu R., Uenishi R., Akashi I., Nakano M., (1986), The use of dyestuff-treated rice hulls for removal of heavy metals from waste water, J. Appl. Polym. Sci., 1, 75-83

Theander O. and Aman P. (1979), Studies on Dietary Fiber: A Method for the Analysis and Chemical, Swedish journal of agricultural research, 26, 46-52.

Treybal, R.E. (1968), Mass Transfer Operations, 2nd ed., McGraw Hill, New York.

Woon Choi N., Mori I. and Ohama Y. (2006), Development of rice husks-plastics composites for building materials, Waste Management, 26 ,189-194. 